\title{
Últimas voluntades de judíos aragoneses formalizadas ante notarios cristianos de Huesca*
}

El autor presenta en este estudio la edición de varios documentos que contienen las últimas voluntades de diez judíos (cinco varones y cinco mujeres), nueve de Huesca y uno de Calatayud, fechados, excepto el primero, en las décadas centrales del siglo XV, y que fueron formalizados ante notarios cristianos. En la medida de lo posible se ha procurado esbozar un perfil biográfico de los testadores con ayuda de datos espigados de los protocolos notariales del Archivo Histórico Provincial de Huesca. Se incluyen una serie de consideraciones relacionadas con la vida económica y los vínculos familiares entre judíos y conversos, todo ello a partir de su reflejo en la documentación escrita.

Palabras Clave: Historia de los judíos; Aragón; siglo XV; últimas voluntades; muerte; cultura notarial; conversos.

Documents Concerning Last wills by Jews Recorded by Christian Notaries of HuEsCA.- This article includes the edition of several documents containing the last wills by ten Jews (five men and five women), nine from Huesca and one from Calatayud, all but the first dated in the mid-decades of the $15^{\text {th }}$ century, that were issued before Christian notaries. As far as possible, the author has tried to sketch a bio of the legators with the assistance of data extracted from the notarial protocols in the Archivo Historico Provincial de Huesca. The author deals, too, with a number of considerations concerning the economic life of these individuals and the familial relationships between Jews and converts.

KeYwords: Jewish History; Aragon; $15^{\text {th }}$ Century; Last Wills; Death; Notarial Culture; Converts.

Durante el transcurso de mi prolongada investigación acerca de la documentación notarial conservada en el Archivo Histórico Provincial de Huesca relativa a los judíos de la ciudad de Huesca en el siglo XV, he

\footnotetext{
"En la realización de este trabajo me he beneficiado de la ayuda del proyecto «Documentos de la Sefarad medieval: estudio y edición de textos hebreos y aljamiados» (Plan Nacional I+D+i MCiIn, FFI2009-10319).
} 
logrado recolectar una serie de textos que tienen cierta uniformidad temática y que, creo yo, permiten incrementar el caudal documental relativo a las últimas voluntades de judíos medievales, ya de por sí importante.

Ofrezco a continuación dicha selección documental, a fin de ponerla a disposición de otros investigadores interesados en trabajos similares ${ }^{1}$. He procedido proporcionando una pequeña introducción a cada uno de los documentos que complemento con datos adicionales que he logrado espigar de entre la documentación notarial, y que se refieren a los protagonistas de los textos que ofrezco, fundamentalmente a su actividad económica.

Se trata de las últimas voluntades formalizadas ante un notario cristiano por cinco varones y cinco mujeres, que, con la excepción de un caso temprano fechado en 1415 , se realizan entre 1441 y 1478 . Se trata de los testamentos de:

\begin{tabular}{lll} 
TESTADOR & FECHA & Heredero unIVERSAL \\
\hline Alazar Çadot & 1415 & $\begin{array}{l}\text { Jamila, madre; Juan Sánchez de } \\
\text { Calatayud, hermano }\end{array}$ \\
\hline $\begin{array}{l}\text { Astruch Xuén, marido de } \\
\text { Astruga de las Ynfantas }\end{array}$ & 1441 & Jucé y Abrahim Xuén, hermanos \\
\hline $\begin{array}{l}\text { Çazón Mazoch } \\
\text { Ezter de Monçón, viuda de }\end{array}$ & 1445 & Martín Pastor, converso, hermano \\
$\quad$ Lopu Alfrangí & 1445 & Jentó Alfrangí, sobrino \\
\hline $\begin{array}{l}\text { Simuel Havingastón, marido de } \\
\text { Bonaffilla }\end{array}$ & 1446 & Haym Avingastón, hijo \\
\hline $\begin{array}{l}\text { Rina d'Alcocombriel, viuda de } \\
\text { rabí Salamón Leví }\end{array}$ & 1451 & $\begin{array}{l}\text { Mosé Almarrán, hijo de su primer } \\
\text { marido }\end{array}$ \\
\hline $\begin{array}{l}\text { Soli Cohén, viuda de Açach } \\
\text { Leví }\end{array}$ & 1456 & \\
\hline $\begin{array}{l}\text { Jucé Luytanes, marido de Ester } \\
\text { Parello }\end{array}$ & 1462 & Ester Parello, mujer \\
\hline $\begin{array}{l}\text { Astruga Acocumbriel, viuda de } \\
\text { Simuel Avín }\end{array}$ & 1472 & \\
\hline $\begin{array}{l}\text { Doña Bienvenida Almagén, } \\
\text { viuda de Acaz Gualit }\end{array}$ & 1478 & \\
\hline
\end{tabular}

${ }^{1}$ Una bibliografía general sobre el tema (actualizada hasta el momento de su publicación) puede encontrarse en la obra de Robert I. Burns, Jews in the Notarial Culture. Latinate Wills in Mediterranean Spain 1250-1350 (Berkeley, etc. 1996). 
Todos son judíos de Huesca, menos el primero, que residía en Calatayud en el momento de su óbito, si bien contaba con parientes en Monzón y Huesca. Además de estos diez documentos, se incluye uno de 1466 acerca del nombramiento de procuradores por la aljama con objeto de gestionar la herencia dejada por un judío habitante en Sicilia, en especial en lo relativo a las mandas destinadas a las sinagogas de Huesca; y, finalmente, otro documento por el que los adelantados de la aljama solicitaban en 1477 al lugarteniente de baile la entrega de los bienes de un judío que había fallecido intestado. En los diez textos que publico, se trata de la distribución que de sus bienes hacían esos judíos en caso de grave enfermedad que pensaban pudiera ser la última. La finalidad del testamento repetida en varios de los textos era

[...] por tal que questiones ni debates no puedan seyer movidos entre mis cercanos parientes en e sobre mis bienes [...] (testamento de Simuel Havingastón).

Como es evidente, el valor de esta documentación, en cuanto a su aportación al conocimiento de las haciendas particulares de los judíos, es bastante limitado, puesto que sólo se explicitan determinados legados y mandas. No debemos olvidar que otras propiedades del individuo no aparecen especificadas, o bien hubieran podido transmitirse a sus herederos por otras vías antes de su fallecimiento. Obsérvese así en el testamento de Çazón Mazoch, en 1445, por el que el interesado deja la legítima a sus hijos, pero nada se nos dice explícitamente del resto de sus bienes. De hecho, en algún otro testamento se menciona la legítima foral aragonesa concedida a los hijos (Soli Cohén); de igual manera, en ocasiones se procede a igualar la herencia de los hijos (documentos núm. 2-3 y 7).

La movilidad de los judíos del reino de Aragón tiene su reflejo en algunos textos, porque encontramos casos ocasionales de judíos originarios de Huesca que habitaban en otros lugares, bien dentro del reino (Alaçar Çadot, en Calatayud) como fuera (Salamón Cazez, en Sicilia), ello sin contar con redes familiares extendidas por localidades más cercanas (Monzón, Montalbán, Ayerbe, Pertusa, etc.).

En suma, la documentación que aporto permiten iluminar aspectos relativos a la vida social de los individuos involucrados, pero menos de aspectos económicos y espirituales. 
Especialmente llamativas son las frecuentes referencias a los parientes directos conversos a los que los testadores dejan legados, como ocurre en siete de los documentos, concretamente en los núm. 1 (Alazar Çadot y su hermano Johan Sánchez de Calatayud), 3 (Çazón Mazoch y su hermano Martín Pastor), 4 (Ezter de Monçón y sus hermanos Bernart de Monçón y Gabriel Monçón), 7 (Soli Cohén y su hijo Johán de Viturián), 8 (Jucé Luytanes y su hermano Johan d'Ara), 10 (Astruga Avín, su sobrino, Pedro, y el «clerigo Osce» don Martín de Risco, cuyo «deudo de parentesco» desconocemos), y quizás 12 (doña Bienvenida Almagén y ¿don Martín de Florenza?) ${ }^{2}$. En este sentido, las últimas voluntades son reflejo de un periodo caracterizado por el drama de las conversiones, pero expresan mejor que cualquier otro testimonio el mantenimiento de vínculos sociales y de afectividad entre judíos y aquellos de sus parientes que habían elegido, por motivos muy diversos, otra opción religiosa. El tratamiento que judíos y convertidos reciben en los testamentos de sus progenitores judíos no deja traslucir aparentemente ninguna preferencia derivada del factor religioso, y si bien en alguno de los testamentos el «espondalero» es el hijo judío (en el de Soli Cohen), en otro lo es el hermano cristiano (junto con otro judío de Zaragoza, en el testamento de Çazón Mazoch). Diferente es, quizás, la intención del codicilo que añade Jucé Luytanes a su testamento, por el que deja a su hermano cristiano únicamente la legítima, mientras que la herencia recae en su mujer e hija.

De la misma manera, algún testamento ilustra la complejidad de las relaciones familiares, como ocurre en el caso de Rina d'Alcocombriel, viuda de rabí Salamón Leví, habiendo estado ambos cónyuges casados previamente con una pareja diferente.

Para que un testamento sea válido es necesario que el individuo esté en su sano juicio, a fin de poder ejercer libremente su capacidad jurídica. Al disponer su última voluntad, algunos manifiestan su voluntad expresa de revocar cualquier testamento o codicilo redactado con antelación (así, en

${ }^{2}$ Fenómeno advertido por E. MARÍn PADILla, «Últimas voluntades judías: testamentos de Duenya Falaquera, Reyna Abenardut y Davit Rodrich (siglo XV)», Anuario de Estudios Medievales 15 (1985), págs. 497-512: 501; y explicado por A. BlASCO MARTínEZ, «Mujeres judías zaragozanas ante la muerte», Aragón en la Edad Media 9 (1991), págs. 77-120: 79, 83-84 y especialmente 106. 
los documentos núm. 3-5, 8 y 10). Los testamentos estudiados aquí son abiertos o nuncupativos, es decir, legitimados por testigos y formalizados ante un notario cristiano que los consigna luego en su protocolo. El número de testigos presentes en el acto varía ligeramente (aunque no sean ellos, sino el notario, los que ofrecen garantías), oscilando su número entre dos, uno judío y otro cristiano (así, en los documentos núm. 5, 8 y 12); o bien, lo que es más frecuente, tres, dos judíos y uno cristiano (documentos núm. 1-4, 6-7 y 10). No es raro que entre los testigos se mencione ocasionalmente un médico (así ocurre en los documentos núm. 2, 3 y 12: maestre Haim Auinardut, maestre Sentó Cavatierra y Francisquo de Palencia).

Estos testamentos siguen en general formalidades semejantes a las de los cristianos en Huesca, lo que no tiene nada de extraño, pues en ambos casos el notario cristiano emplea terminología usual en la práctica documental $^{3}$. Pero sí se observan algunas peculiaridades. Por un lado, la invocación es a Dios (así en los documentos núm. 1-5, 7-8 y 12) y a su Gloria. En contadas ocasiones se incluye alguna fórmula religiosa (en los testamentos de Simuel Havingastón -que reproduzco a continuación- y Soli Cohén):

[...] Como toda persona en carne puesta a la muert corporal sia subjugada por el peccado que el primer hombre, stando en parayso terrenal perpetro en traspassar el mandamiento de su Creador, e por seguient en la creatura no sia cosa mas cierta que la muert e menos cierta que la hora de aquella [...]

No abundan en los textos recopilados las referencias a mandas piadosas. Encontramos en una única ocasión una manda para una «confraria que lieuan los muertos» (Ezter de Monçón); en otra, no se olvida a los rabinos de la comunidad que se ocuparían de llevar el cadáver, ordenando que «pagades los rabis por su anima» (doña Bienvenida de Almagén). Hubiera sido interesante poder conocer en detalle el texto del testamento de Salamón Cazez, un residente en Sicilia al momento de su muerte, ya que la procuración aprobada por la aljama para reclamar sus bienes, alude de manera genérica a la posibilidad de que estos hubieran sido «lexados a la dita aljama sian si a la sinoga mayor de aquella como a las otras sinogas e spitals de la dita aljama».

\footnotetext{
${ }^{3}$ Acerca de la estructura del documento testamentario, véase Blasco Martínez, «Mujeres judías zaragozanas ante la muerte», pág. 100.
} 
En algunos casos se encarga la realización de los ritos funerarios y de aniversario preceptivos en el fosar judío:

[...] do me sian feyta toda mi funeralia de mi deffunsion, novena e cabo d'anyo segunt costumbre e uso de judios [...] (testamento de Jucé Luytanes) ${ }^{4}$.

También se especifican mandas para los encargados de hacer la tumba (testamentos de Ezter de Monçón y Rina d'Alcocombriel). Encontramos reiterado la referencia al lugar de enterramiento, el «fossar» de los judíos de Huesca (documentos núm. 2-8, 10 y 12), situado en "Sant Jorge», como señala claramente el testamento de Simuel Havingastón. En algunos casos, el testador pide ser inhumado al lado de un pariente o bien del cónyuge fallecido con anterioridad (o, eventualmente, en el futuro). Así, en los testamentos de Ezter de Monçón («en do jazen mis parientes»), Rina d'Alcocombriel (junto a los dos hijos de sus dos matrimonios), Soli Cohen (al lado de su marido), o Jucé Luytanes (que prevee el entierro futuro de su esposa al lado de su tumba).

Encontramos también determinadas mandas destinadas a realizar monumentos funerarios para parientes y allegados (documentos núm. 4-6) 5 Siguiendo un uso frecuente en la tradición judía, doña Bienvenida Almagén, pide en su testamento que su lápida «sia feyta dentro l'anyo que sia morta».

El heredero universal varía de un testamento a otro, lo que nos da idea de la distinta intensidad de las relaciones familiares y sociales de los testadores: la madre judía y el hermano converso en el de Alazar Çadot; los hermanos en el de Astruch Xuén; el hermano converso en el de Çazón Mazoch; el sobrino en el de Ezter de Monçón; el hijo en

${ }^{4} \mathrm{Y}$ véanse formulaciones semejantes en los testamentos de Çazón Mazoch y Rina d'Alcocombriel. En relación a esto y a lo siguiente, contrástese, sin embargo, con lo señalado por Blasco Martínez, «Mujeres judías zaragozanas ante la muerte», pág. 101.

${ }_{5}^{5}$ Precisamente, hace unos años publiqué una carta de obligación por la que en 1409 el médico Ahym Avinardut establecía un contrato con un piquero cristiano para hacer dos sepulturas para sus padres en el «fossal nuevo de los judios de Huesca», cf. E. BENEDicto Gracia «Los médicos judíos de Huesca, según los protocolos notariales del siglo XV», Sefarad 68 (2008), págs. 55-87: 77. 
el de Simuel Havingastón; un hijo del primer marido en el de Rina d'Alcocombriel; y en el de Jucé Luytanes, su mujer. En el caso de los «espondaleros» ('albaceas') -allí donde se mencionan-, su elección suele recaer por igual en allegados a la familia y en familiares directos: un judío de Huesca en el de Ezter de Monçón; la mujer e hijo en el de Simuel Havingastón; otros dos judíos de Huesca en el de Rina d'Alcocombriel; y en el de Jucé Luytanes, su yerno y dos judíos de la ciudad, «honorables e caros amigos».

\section{LOS TESTADORES JUDÍOS Y SU ACTIVIDAD ECONÓMICA}

Alazar Çadot, judío de Calatayud, deja en 1415 por herederos universales a su madre y a un hermano acristianado. No he logrado hallar ningún dato relativo al testador en los protocolos notariales de Huesca y, en consecuencia, habría que concluir que su vida se desarrollaría en Calatayud, aunque mantiene estrechos vínculos familiares con judíos de Huesca y Monzón. De hecho, su madre pertenecía a la importante familia de los Avinardut oscenses, pues era hija del finado maestre Alazar Avinardut. Por el contenido del documento, podemos deducir que en el momento de redactarse, Alazar sería aún joven. El hermano del testador, Juan Sánchez de Calatayud (ol. Calema Çadot), era un converso habitante en Monzón. Entre las obligaciones que impone Alazar a sus herederos, incluía el pago de una cantidad a su padrastro Bonina, un mercader judío de Monzón, en compensación por los años que este había corrido con su manutención, y también hacia rabí Jacob Avinardut (quizás, su tío materno), y al hijo de este, Alazar Avinardut.

En cuanto a Astruch Xuén, se conservan bastantes referencias a él en los protocolos notariales de Huesca, desde 1428, cuando aparece mencionado como testigo de una comanda (prot. 178, fol. 253), hasta 1439, es decir, dos años antes de que formalizara su testamento. Conocemos su actividad crediticia en la ciudad, y como es de esperar en los protocolos notariales, la documentación lo presenta con frecuencia en su papel de provisor de crédito ${ }^{6}$, aunque no es muy clara en cuanto a sus ocupacio-

${ }^{6}$ Sin tratar de ser exhaustivo, en 1428 aparece ya mencionado en los protocolos como testigo de una comanda (prot. 178, fol. 253). En 1431 se registran sendas comandas que 
nes, ya que algún documento lo presenta como zapatero, o bien como trapero ${ }^{7}$. Pero, en general, la imagen que de él ofrecen los protocolos es la de eficaz prestador. A título de ejemplo, en el último de los años en que aparece citado, 1439, está prestando (nominalmente), entre otros, un total de 4.607 sueldos repartidos en 16 comandas, además de otros 57 florines distribuidos en tres comandas adicionales ${ }^{8}$.

Es el suyo un testamento bastante detallado, a partir del cual sabemos que estaba casado con Astruga de las Ynfantas. Al momento de redactarlo tenía tres hijos menores de edad, un varón (Azareha) y dos niñas (Mira y Sol), a las cuales deja dos legados de 150 florines para sufragar su dote. Al igual que se repite en otros testamentos, una de las primeras instrucciones contenidas en el texto es su voluntad de ser enterrado en el fosar de los judíos de la ciudad, donde ya reposaban sus parientes.

A su hijo Azareha deja el tercio de las propiedades que comparte con sus dos hermanos, Jucé y Abrayme Xuén, las cuales detalla en el testamento, y que consisten en unas casas en la ciudad y varias fincas rústicas en los alrededores ${ }^{9}$, además de 200 florines que recibiría al cumplir 18 años (en caso de que contrayera matrimonio antes de esa edad, recibiría esa cantidad, aunque la perdería si no estuviera casado a los 20 años, si bien sus tíos se seguirían encargando de correr con los gastos de boda). En caso de que falleciera Azareha, su parte quedaría para las niñas. Aparte de los gastos de mantenimiento de los hijos, se incluye una partida para la educación del hijo varón.

realiza de 100 y 175 s[ueldos] (prot. 180, fols. 85 y 89). De nuevo, en 1432 otra comanda por 4 cahíces de trigo (prot. 37, fol. 3v), y en ese año mantiene un pleito con un cristiano (prot. 13, fol. 55v). De 1435 se conserva una comanda de un elevado préstamo de 25 florines. En 1436, los protocolos incluyen 13 comandas por las que presta por valor nominal de 1496 s y 30 florines (prots. 78-79, passim). 1437 es el año en el que registra más actos protocolizados: 32 comandas por valor nominal de 371 s y 36 florines, además de cereal, hasta nueve aparentes compras de lana, etc. (prot. 97, passim).

${ }^{7}$ Una comanda de préstamo de $108 \mathrm{~s}$ de 1429 lo califica de «zapatero»; y otra de 2 cahíces de trigo, de «trapero» (prot. 179, fols. 53 y 90).

${ }^{8}$ En ese mismo año comparece junto a un deudor que recibe $3.000 \mathrm{~s}$, comprometiéndose a pagar $500 \mathrm{~s}$. al año. Presta cinco cuartales de trigo. Compra cinco veces lanas en el año. Los datos relativos a 1439 están extraidos del prot. 215.

${ }^{9}$ Se conserva una mención a la compra en 1436 de una viña en el término del Algarde de Huesca por 112 florines (prot. 38, fol. 44). 
Deja como tutores y curadores de sus hijos a su hermano Jucé y a su cuñado Salamón de las Ynfantas. El testamento incluía también una manda para la dote de Astruga Cazez, de la que ignoramos su parentesco, si lo tenía, con el testador. Una vez concluida esta distribución, nombra como herederos universales a sus hermanos Jucé y Abraham Xuén. El documento incluye una anotación notarial al final, donde se detalla que se haga «con quinyan gamur, mearsan» (es decir, קנין גמור מעכשיו). Y concluye con una declaración de sus hermanos, asegurando la nulidad de dicha donación en caso de que el testador escapara de la enfermedad.

Çazón Mazoch hace su testamento en 1445, y aparece mencionado en los protocolos notariales entre 1428 y 1439. Su ocupación profesional como baldresero («çurrador»y «blanquero») se refleja en unas cuantas referencias documentales ${ }^{10}$. No parece que tuviera una situación económica estable, de hacer caso a las referencias a deudas debidas, a título individual, o junto con otras personas ${ }^{11}$. En otras ocasiones, aparece como testigo de diversos actos notariales ${ }^{12}$.

A las cláusulas previsibles en el testamento (enterramiento en el fosar de los judíos, celebración de la «nouena e cabo d'anyo»), se añaden otros datos relativos a sus hijos, Reyna y Abraymico. Hermano suyo es el «mercadero» Martin Pastor, un converso, al que deja como tutor y curador de sus hijos, junto a Jacob Seneor, judío de Zaragoza ${ }^{13}$.

${ }^{10}$ Como baldresero había contraido en 1430 una deuda de 50 s con Jucef Adida (prot. 32, fol. 37). Referencias a compra de pieles y corambres en 1436 (prot. 76, fols. 6, 26, 33), 1437 (prot. 97, fol. 3v), y 1439 (prot. 79, fol. 26 y prot. 97, fol. 3v). Vende en 1439 cien robas de lana a Barcelona a $18 \mathrm{s,} 3 \mathrm{~d}$ [ineros] (prot. 215, fol. 87).

${ }^{11}$ Deuda de una comanda suscrita con otros en 1428 (prot. 178, fol. 79); otras deudas registradas en 1428 y 1429 (prot. 178, fol. 243; prot. 179, fols. 85 y 228, en este último caso, contraída con otros judíos). En 1428 contraía una deuda de 60 florines para pagar una casa que había comprado (prot. 178, fol. 79). En 1439 se registra un préstamo suyo en comanda por 29 florines (prot. 79, fol. 28v).

${ }^{12}$ En 1429 es mencionado como testigo de una comanda (prot. 179, fol. 230), y también del testamento de Haín Gastón, «menor de dias» (prot. 179, fol. 260).

${ }^{13}$ Se podría identificar con el Jacó Senyor, mencionado como participante en 1447 en una reunion de la aljama de Zaragoza para otorgar un censal, M. SERRAno y SAnz, Orígenes de la dominación española en América (Madrid 1918), doc. 32, pág. 477, o bien, con don Jacob Seneor, beror o dayyán de la aljama de Zaragoza en 1465, cf. J. L. LACAVE Riaño, «Pleito judío por una herencia en aragonés y caracteres hebreos», Sefarad 30 (1970), págs. 325-337: 337. 
De Simuel Havingastón encontramos referencias en los protocolos notariales entre 1428 y 1441, aunque su testamento no lo redacta hasta 1446. Sabemos que en 1428 poseía una casa junto al midrás, que tiene que obligar a causa de una deuda que tenía de 106 sueldos (prot. 178, fol. 256). Ese mismo año actúa como procurador de la aljama (prot. 280 , fol. 202) y en 1429 , figura en una referencia documental como sastre (prot. 179 , fol. 38) ${ }^{14}$. Con posterioridad aparece mencionado sólo de manera circunstancial $^{15}$.

$\mathrm{Su}$ testamento es bastante parco en datos. Reserva a su mujer Bonafilla el disfrute de sus bienes durante su vida, aunque el heredero universal es su hijo Haym, y ambos, mujer e hija son nombrados albaceas. Más interesante es subrayar el hecho de que su mujer aprueba explícitamente las disposiciones testamentarias, tras lo cual, el mismo testador añade una suscripción hebraico-aljamiada escrita de su puño y letra con cierta torpeza, ya que desliza algún error y falta ortográfica (síncope en una de las palabras aljamiadas, y confusión de kaf por qof en קתבתי/כתבתי).

No es difícil precisar el perfil profesional de Jucé Luytanes a partir de las escasas menciones que acerca de él encontramos en los protocolos notariales entre $1435^{16}$ y 1446 , pues algunas de ellas apuntan a actividades relativas a la curtiduría de pieles ${ }^{17}$, aunque desconocemos en detalle su situación económica. Después de 1446 y hasta el momento en el que redacta su testamento en 1462 no volvemos a encontrarnos con noticias suyas en los protocolos.

Deja sus bienes muebles e inmuebles a su mujer Ester Parello, aunque reserva un huerto que posee junto a su vivienda a su hija Horo. A su herma-

${ }^{14}$ En 1428 y 1429 figura repetidamente como testigo en albaranes (prot. 178, fol. 51, $51 \mathrm{v}$ y 278 ) y comandas (prot. 178 , fol. $71 \mathrm{v}$ y 74 ; prot. 179 , fol. 38 y $90 \mathrm{v}$ ).

${ }^{15}$ En 1429 figura como testigo en una sentencia entre cristianos (prot. 179, fol. 153). En 1441, da a Miguel Ferrer de Huesca 2.333 s en pago de 1.000 sacas de carbón (prot. 217, fol. 40v).

${ }^{16}$ La primera mención en los protocolos es como testigo de una comanda (prot. 181, fol. 181).

${ }^{17}$ En 1440 devuelve deudas contraídas con Marín Pastor, blanquero de Huesca (prot. 215, fol. 92), y también vende a Valencia, junto con otros, 40 docenas de baldrases a $5 \mathrm{~s}$ la docena (prot. 81, fol. 33). En 1446 aparece dando en comanda 12 cahíces de yeso (prot. 86 , fol. 208), y vende 25 robas de «rebol» ('lana de vellón'). 

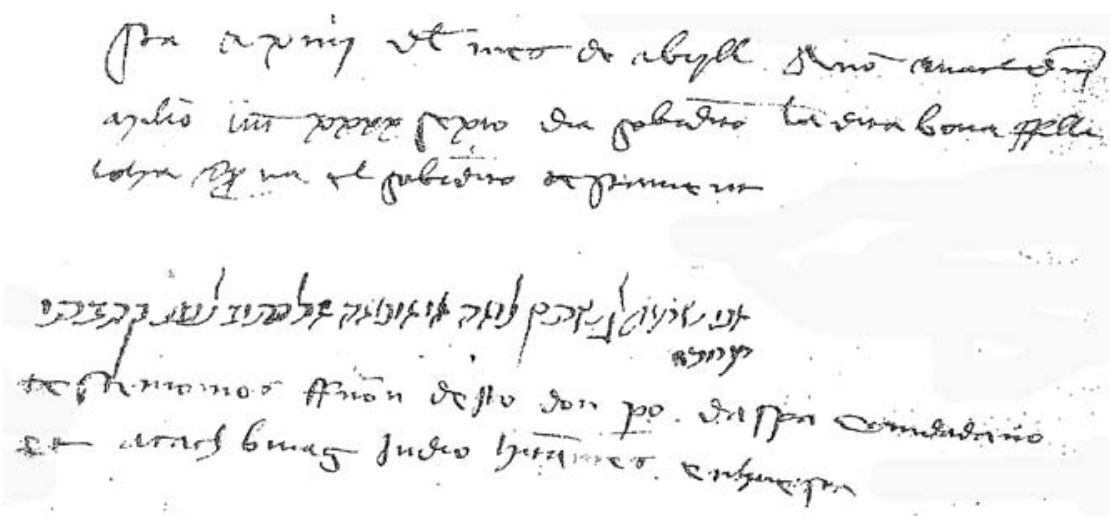

Figura 1: Suscripción hebraica hológrafa del testamento de Haym Havingastón (Archivo Histórico Provincial de Huesca, prot. 189, notario Juan Ascaso, fol. $63 \mathrm{v})$.

no converso, Johan d'Ara concede únicamente la legítima, quitándole cualquier otro derecho que este pudiera reclamar mediante un codicilo añadido el mismo día del testamento. Deja de albaceas a su yerno y a dos judíos «honorables e caros amigos» de Huesca, a fin de gestionar sus bienes.

Carecemos de información respecto a Salamón Cazez, aparte del hecho de que los representantes y autoridades de la aljama de judíos de Huesca reunidos en 1466 en la sinagoga mayor nombran como procuradores para cobrar en su nombre los bienes que Salamón hubiera dejado a la aljama y a sus instituciones religiosas (sinagogas y hospitales). El hecho de que los procuradores elegidos sean dos judíos de Calatayud, don Mosé Catorze y Mossé Passagón -ausentes de dicha reunión-, hace pensar en que se trataría de dos viajeros ocasionales (¿mercaderes?) desplazados a Sicilia para otros menesteres.

Desconocemos la fecha exacta del fallecimiento intestado de Mossé Hadida. Cuando en 1477 la aljama de Huesca reclamaba los bienes de sus hijos, hacía años que había finado, puesto que ya el 18 de julio de 1470 aparece mencionado Salamón Ambrón como tutor de sus hijos Jucé y Alazar Adida (prot. 201, fol. 37), por lo que es muy probable que hubieran surgido problemas entre la aljama y las autoridades reales, pese al 
hecho de que el rey Pedro el Ceremonioso había advertido de que en caso de que un judío muriera intestado, sus bienes pasarían a la aljama, a fin de que esta procediera a su reparto según su ley.

Contamos con datos tempranos acerca de un Mossé Hadida, homónimo del anterior, que en 1425 aparece prestando una comanda (prot. 11032 , fol. 5v), aunque consta fallecido pocos años después, pues en 1431 su hijo Jucé otorga un albarán como heredero suyo (prot. 180, fol. 185). Este Jucé aparece mencionado como prestamista con bastante frecuencia. Es en 1463 cuando se registra una mención a Duenya Alazar, mujer que había sido del citado Mossé, ya fallecido, que recibía una deuda que tenían con su marido (prot. 30, fol. 14). A partir de esta fecha no volvemos a encontrar ninguna actividad económica de miembros de esta familia reflejada en los protocolos notariales.

Desconozco el grado de parentesco de los anteriores con el Mossé Hadida, acerca del cual requieren los adelantados de la aljama la ejecución de bienes que tenía en su casa (documento núm. 11). Cuando el lugarteniente de baile entra en su casa encuentra algunos libros y una documentación económica importante; «vn Genesi en ebrayco, vn liuro de Profecias de Ysayas»; además de ello, encuentra varias ligarzas y cajas de documentos, bastantes de ellos comandas (una de ellas con 41, y otra con 31 cartas), además de varios libros de deudas, uno «scripto en judayco», y finalmente, un documento de propiedad de un asiento en una de las sinagogas oscenses, la de Sant Cebrian. A ello se añadía diversos objetos mobiliarios, entre los cuales destacaba «vn bancal encima armas nobles».

\section{LAS FAMILIAS DE LAS TESTADORAS JUdÍAS DE HUESCA}

A diferencia de lo que suele ocurrir con los varones, seguir la pista en los protocolos notariales de Huesca de las mujeres cuyos testamentos presento (Ezter de Monçón, Rina d'Alcocombriel, Soli Cohén, Astruga Avín, y doña Bienvenida Almagén) es una tarea difícil, sino imposible. Es como si hasta que formalizaron su testamento no hubieran tenido necesidad de acudir al notario. He preferido tratar de todas ellas aparte, aunque la carencia documental se ve subsanada en determinados aspectos 
por la información que nos proporcionan los testamentos y que ilustra la complejidad de las relaciones familiares de alguna de ellas que incluían a conversos y, anecdóticamente, de la vida conyugal de alguna de ellas.

Fuera de la notable información que nos proporciona su testamento, no he logrado hallar datos acerca de Ezter de Monçón en otros protocolos. Sabemos que en 1445, al momento de formalizar su testamento, estaba ya viuda de Lopu Alfrangí. Dejaba por herederos universales a su sobrino -e hijo de su marido y de su hermana Oro Monçón, aparentemente fallecida $^{18}$-, Jentó Alfrangí ${ }^{19}$. De los legados que incluye el testamento, sabemos que Ezter tenía dos hermanos conversos, uno ya fallecido, Bernat de Monçón, y otro, Gabriel Monçón, que era vecino de Montalbán. A este y a los hijos del anterior deja simplemente la legítima.

Al igual que expresan otros judíos de la ciudad en sus testamentos, Ezter determina enterrarse en el fosar de los judíos de Huesca, «en do jazen mis parientes». En este sentido es interesante reseñar que varias de las mandas que incluye en su testamento están referidas a ritos funerarios, desde el coste de la tumba para dos allegados (don Jacob Baço y don Haym Alcocombriel) -de los que ignoramos su parentesco o relación con Ezter-, hasta una manda para la «confraria que lievan los muertos», entre otras.

De Rina d'Alcocombriel sabemos que al momento de formalizar sus últimas voluntades en 1451 estaba viuda de su segundo marido, rabí Salamón Leví, a cuyo lado ordena enterrarse en el fosar de los judíos. De hecho, había contraído matrimonio en primeras nupcias con el también finado Mosé Almarrán. Ahora bien, su segundo marido, rabí Abraham, había estado casado con otra mujer, pues el testamento de Rina menciona un legado para su hijastra Astruga Leví, que estaba casada con David de las Ynfantas.

${ }^{18}$ No hay que identificarla con su homónima Oro, esposa de Samuel Rimoj de Monzón, cuyo testamento hebreo está fechado en 1463, cf. M. Blasco Orellana, J. R. MAGDalena Nom de Déu, M. A. Motis Dolader, «Últimas voluntades de los judíos en Aragón: el testamento de doña Oro, esposa de Samuel Rimok, judía de Monzón (1463)», Materia Giudaica 14 (2009), 431-459.

${ }^{19}$ Aunque la única mención que hay en el texto a Oro no indica explícitamente que esta hubiera fallecido ya, la propia situación conyugal de Ezter, y el hecho de ignorarla en su testamento, hace pensar en un matrimonio de levirato entre Ezter y Lopu Alfrangí. 
Del testamento deducimos que Rina habría tenido, al menos, tres hijos, dos del primer marido y uno del segundo. Dos de los tres habrían fallecido ya (Jucefi Almarrán y Astruch Leví), quizás recientemente, puesto que deja una manda para la realización de sendas tumbas, además de la suya propia. El heredero universal de Rina es un hijo de su primer matrimonio, aún menor de edad, Mosé Almarrán, para el cual determina un tutor y curador en la persona de don Simuel Usiello, un judío de Huesca, que junto a Mosé Ardit son los albaceas testamentarios.

En cuanto a Soli Cohén, viuda de Açach Leví de Huesca e hija de Jucé Cohén, sabemos que tenía varios hijos ya casados, de ellos, al menos, uno acristianado (Johán de Viturián) y otros dos judíos (Jamila y Abraym Leví). Alega en sus últimas voluntades que, al momento de formalizarlas, poseía muy pocos bienes. Al igual que como hemos visto en otros casos manda ser enterrada en el fosar de los judíos, «cerca el dito Acac Leui». Apenas deja la legítima a sus dos hijos varones. A su hija y a sus dos nueras -una judía, la otra cristiana-, lega varias prendas de vestir («manto de bruneta», «grimen negro forrado de penya blanca», «saya jusana de bruneta»). Será su hijo judío Abraym, el albacea encargado de gestionar los bienes restantes cuyo detalle no menciona en el testamento.

Al igual que Soli Cohén, Astruga Acocumbriel, viuda de Simuel Avin, tiene parientes cristianos que aparecen mencionados como beneficiarios de legados en su testamento de 1472 que, no obstante, no menciona ningún hijo. De hecho, entre los beneficiarios (en bastantes casos calificados de «deudos de parentesco») se cuentan sus sobrinos Pedro y Rahel, la mujer de Haym Alcastiel de Ayerbe. Dejaba como herederos de sus bienes restantes a cuatro sobrinos, hijos de su hermano Astruch Cocumbriel (Salamón, Simuel, Jucé y Soli).

Las últimas voluntades de una judía formalizadas ante notario en Huesca que he logrado hallar están datadas en 1478, y corresponden a doña Bienveniste Almagén, viuda del pellicero don Acaz Gualit. El contenido del documento es interesante, puesto que incluye una buena cantidad de legados, además de un inventario de bienes muebles. Sabemos que su marido había sido regidor de la aljama de Huesca en 1466 (véase, documento núm. 10), aunque el testamento no menciona 
ningún hijo, pues los legados en forma de legítima a sus parientes más cercanos van destinados a dos sobrinos, Hezmel y Jamilica, hijos de su cuñado Jacob Gualit. Sí deja también semejantes legados a Jamyla, antigua servidora, además de a otros individuos que no he logrado identificar. 


\section{TeXTos}

He añadido puntuación moderna allí donde la he creido necesaria. Además, he optado, a diferencia de trabajos míos anteriores, por no acentuar el texto. Añadidos y comentarios míos sobre el texto aparecen introducidos entre corchetes ([ ]), y las palabras o frases que aparecen interlineadas, o al margen, se han situado entre barras inclinadas (//). En algunos casos, he preferido dejar irresueltas lecturas dudosas, de lo que advierto oportunamente ${ }^{20}$.

1

1415, septiembre 3, Huesca

Alazar Çadot, judío de Calatayud, expresa sus últimas voluntades a favor de su madre Jamila, hija del médico Alazar Avinardut, y de su hermano Juan Sánchez de Calatayud (ol. Calema Çadot), ambos residentes en Monzón ${ }^{21}$.

AHPH, prot. 19 (notario Pedro de Igriés), fol. 37r

$$
\begin{aligned}
& { }_{37 r} \text { Kalendas septembris, die dominica, anno a Nativitate Domini } \mathrm{M}^{\mathrm{o}} \mathrm{CCCC}^{\mathrm{o}} \\
& \mathrm{XV}^{\mathrm{o}} \text {. }
\end{aligned}
$$

En nombre de Dios, etc. Yo Alazar Çadot, fillyo de Açach Çadot, judio de Calatayu, quondam, jaciendo enfermo, facio e ordeno mi ultimo testamento, por tenor del qual lexo a Jamila, fillya de maestre Alazar Auinardut, quondam, e a Johan Sanchez de Calatayu, olim clamado Calema Çadot, hermano mio, habitante en Monçon, todos mis bienes mobles e sedientes e todos mis nombres e acciones, assi que aquellos partan entre si por yguales partes, e a los quales, madre e hermano mio lexo, pago, instituo e ordeno herederos mios universales, en tal manera e con aquesta carga que ellyos satisfagan, paguen e contenten a Bonina, mercader judío de Monçon, padrastro mio, todo lo que quiere que por mi ha espendido el dito Bonina en ferme, mostrar letras e scrivir e en comer, bever, vestir, calçar e en manera otra alguna, de las quales expensas sia creydo el dito Bonina por jurament suyo, el qual faga segun ritu de judios. Et encara quiero que satisfagan a Jacob Auinardut, judio Osce, qui quier que ha espendido por mi e por mi

${ }^{20}$ Agradezco a la profesora Asunción Blasco (Universidad de Zaragoza) su ayuda en la resolución de algunas dudas de transcripción.

${ }^{21}$ Publicado anteriormente en Benedicto Gracia «Los médicos judíos de Huesca», 78 , doc. 3 . 
enfermedat e espendra d'aqui adelant encara satisfaga las otras mis injurias que por verdat seran trobadas.

Actum Osce, III dias de setiembre, anno MCCCCXV ${ }^{\circ}$. Testes: don Miguel de [ileg.], Sentó Tuba e Sentó Almuzar, judio Osce.

Item lexo a Alazar Auinardut, fillyo de rabí Jacob Abinardut, judío Osce graciose e por algunos servicios que me ha feyto, quaranta florines.

2

1441, agosto 15 , Huesca

Testamento de Astruch Xuen, marido de Astruga de las Ynfantas.

AHPH, prot. (not. Juan de Ara), año 1441, fols. 181v-185r

Testament de Astruch Xuen.

In Dei nomine, amen. Die XV agusto e anno quo supra, Osce. Que yo Astruch Xuen, judio Osce, stando enfermo de mi persona, cassando e anullando etc., ordeno el present mi ultimo testament e voluntat, el qual ordeno e departo de mi persona e bienes en la forma e manera siguient:

Et primerament quiero, mando e ordeno que cada e quando a Dios nuestro senyor plazera que mi anima pase de ste mundo al otro, que ${ }_{182 r}$ mi cuerpo sia enterrado en aquel fosar do los otros judios de la dita ciudat se costumbran enterrar, en aquella partida do jazen mis parientes

Item quiero que mi defunsion sia feyta segunt conviene a mi e se costumbra fazer en la juderia de la dita ciudat.

Item quiero, mando e ordeno que todos mis deudos e injurias sian pagados aquellos que por verdat seran trobados.

Item lexo a mi muller, Astruga, de gracia special, dozientos sueldos ultra sus dotes.

Item lexo e do a Azaheya, fillyo mio, el terz e part tocant a mi en conpanya con mis ermanos Juce e Abrayme Xuen, en las heredades infrascriptas: primerament el terz de hunas casas con cellyero, vaxiellya e huerto do habitamos, sitiadas en el barrio de Amiellyas, que conffrontan con casas de los herederos de Abrayme Alcastiel e con casas de David de las Yfantas e carrera publica. Item mas, el terz de otras casas sitiadas ally mesmo, que conffrontan con casas de maestre Necim e casas de [sic] de los herederos de Juce Auincazer/darrera [ileg.]/. Item el terz de 
hun plantero en Conillymique [ $i s i c$ ?] que conffronta con plantero de los herederos de Miguel de Lafuent e con canpo de Pero Symon, franco e quito. Item el terz ${ }_{182 v}$ de hun plantero en la Alquerdia [¿sic?], que conffronta con vinya de Bernart de Sanguesa e vinya de Pero Sellya, franco e quito. Item el terz de hun plantero sitiado en el termino de la dita ciudat clamado Altocorum [ ¿sic?], que conffronta con plantero de Vidal Cabanyas e con plantero de Johan de Gallyur. Item el terz de huna vinya sitiada en el termino de Miquera, termino de la dita ciudat, que conffronta con vinya de Garcia Montaragon e con el guerto de Miquera e con carrera publica; faze siet sueldos de trehudo e dos dineros a Sixena.

Item mas do e lexo al dito Azarhea dozientos floris de oro e peso de Aragon, los quales quiero que le sian dados quando sera de edat de diez e hueyto anyos. Et si ante casara, que aquellos haya a recebir e cobrar quando casara. Et si por ventura el dito Azarhea no casava daqui a que fuere de edat de vint anyos, que no sian tenidos de darle ne daqui a que haya los ditos vint anyos, et aquellos pueda recebir quando sera de aquel tiempo, casando o no casando. Empero quiero que los ditos Jucen e Abrayme sian tenidos fazerle la mesion de las bodas de comer, bever, vestir e calcar, a el e a su muller, de manera que le finquen quitos los ditos $\mathrm{CC}$ florins.

${ }_{183 r}$ Item do e lexo a Mira, fillya mia, cient cinquanta florins de oro pora ayuda de su matrimonio, los quales le sian tenidos dar quando sera de edat de quinze anyos.

Item do e lexo a Sol, fillya mia, pora ayuda de su matrimonio, cient e cinquanta florins de oro, los quales le sian tenidos dar quando sera de edat de quinze anyos.

Enpero quiero que si contecia morir el dito Azarhea menor de edat pora ordenar, que en aquel caso todos los ditos bienes por mi a el lixados finquen a las ditas Mira e Sol, fillyas mias, las quales partan los ditos bienes por yguales partes. Et si por ventura defallya e contecia morir alguna delas ditas Sol e Mira, o de qualquiere dellas, o entramas menores de edat para ordenar en los ditos bienes por mi a ellyas o a qualquiere dellas lixados, sian e tornen al dito Azarhea, fillyo mio.

Item quiero, mando e ordeno que los ditos Juce e Abrahan Xuen, ermanos mios, sian tenidos dar la provision de comer, bever, vestir e calcar a los ditos Azarhea, Mira e Sol, e al dito Azarhea dar maestros en la escuela, daqui a que sian de /la/ edat sobredita, et (***) quiero que el dito Azahea [sic] no pueda demandar ninguna cosa del auanz / [ileg.] / que sera sallido de las ditas heredades ni de los ditos dozientos florins por mi a el lixados. Item mando que sian dados a Astruga Cazez, fillya de ${ }_{183 v}$ don Acach Cazer, pora ayuda de su matrimonio, cient sueldos. 
Item lexo tutores e curadores de las personas e bienes de los ditos Azahea, Mira e Sol, fillyo e fillyas mias, al dito Juce Xuen, ermano ermano [sic] mio e a Salamon de las Yfantas, cunyado mio, antramos ensemble e a cada uno dellos por si, dandoles todo aquest poder que a tutores testamentarios se puede dar e atribuyr, segunt ley e ritu de judios.

/Et nos ditos Juce e Abraym loamos e aprovamos todo lo sobredito e nos obligamos aquello conplir, tener e observar et non contravenir con scritura casa *** actam./

Item complidas todas e cada unas cosas sobreditas e por mi mandadas fazer, todos e qualesquiere otros bienes mios asi mobles como sedientes, dreytos, nombres e acciones a mi acatantes e pertenescientes o acatar e pertenescer podientes e denientes dentro en el regno de Aragon o fuera de aquel /lexolos todos a vos ditos Juce e Abrahim Xuen ermanos miios, a los quales instituesco herederos mios universales e que partan por mediales partes/, atendidos e considerados los muytos agradables plazeres, onras e buenos merecimientos que vos Juce Xuen e Abraham Xuen ermanos mios me havedes feytos, etc. Por esto, fago a vos donacion e cesion pura e perfecta feyta entre vivos a vos ditos Juce e Abraham Xuen ermanos mios de todos e qualesquiere otros bienes mios assi mobles como sedientes ${ }_{184 r}$ como son dineros, florins, oro, plata, comandas, deudos, depositos, casas, casales, vinyas, canpos, ropas de lino, de lana, de seda e de coton, trigo, centeno, ordio, ceuada, bestias e otros qualesquier bienes assi mobles como sedientes. Et quiero que hayan aquellos por suyos por dar, vender, camiar, alienar, empenyar, etc. Et por tal que la present donacion haya firmeza e valor en judicio e fuera de judicio do a vos fiança segunt fuero a Açach Cazez [sic], judio Osce, qui present yes, qui tal etc. Fiant omnia in forma debita ut deçet con quinyan gamur mearsan.

Testes: Lazaro Bonanat, maestre Haim Auinardut, metce, et Symuel Actulhacer, judios Osce.

Eadem die etc., que nos Juce Xuen e Abrayme Xuen, atendido e considerado que vos Astruch Xuen, ermano nuestro, a nos hayades feyto donacion e cesion segunt actis ut supra, por esto queremos que si a Dios nuestro senyor plazera vos scapar de aquesta enfermedat en que de ${ }_{184 \mathrm{v}}$ present soz puesto, queremos que en aquel caso la dita donacion finque e fora nulla, casa e vana e havida por no feyta et que en judicio ni fuera de judicio valor no haya mas que si nunca fues feyta. Requirientes de predictis etc.

Testes qui supra. 
1445, abril 5, Huesca

Testamento de Çazón Mazoch, alias Pastor, habitante de Huesca.

AHPH, prot. 84 (notario Juan de Ara), fols. 100v-101r forma].

Testament de Çazon Mazoch, alias Pastor [ad marginem: fuit tradita in

In Dei nomine amen. Die $\mathrm{V}^{\mathrm{a}}$ aprilis e anno quo supra, Osce. Que yo, Çazon Mazoch, alias Pastor, judio, habitant en la ciudat de Huesca, estando enfermo de mi persona e loado el nombre de nuestro Senyor Dios, seyendo en mi buen seso, etc., casando e anullando todos e qualesquiere testaments, etc., ordeno el present mi ultimo testament.

Et primerament eslio mi sepultura en aquel fosar en do se costumbran soterrar los otros judios de la dita ciudat.

Item quiero, mando e ordeno que mis defunsion, nouena e cabo d'anyo me sian feytas segunt a mi conviene e yes la costumbre en la dita aljama.

Item quiero, mando e ordeno que todos mis deudos e injurias sian pagados, todos aquellos que por verdat seran trobados.

Item lexo a Reyna e Abraymico Çazon [sic, por Mazoch], fillyos mios, por part e por legitima de bienes mobles e sedientes, a cadauno dellos, cada cinquanta sueldos dineros jacenses. Et con aquesto quiero, mando e ordeno se tiengan por contentos de toda e qualquiere part e dreyto a ellyos e qualquiere dellos por te- ${ }_{101 r}$ stament /e acatant/ en mis bienes asi mobles como sedientes.

Item complidas /e feytas/ todas e cada unas cosas por mi mandadas fazer, todos e qualquiere otros bienes mios, asi mobles como sedientes, etc., lexolos todos al honrado /Martin/ Pastor, ermano mio, mayor de dias, mercadero, vezino de la dita ciudat, al qual instituesco heredero mio universal.

Item lexo tutores e curadores de las personas e bienes de los ditos Reyna e Abraemico fillyos mios /antramos ensemble [isic?]/, al sobre dito Martin Pastor, mayor de dias, ermano mio, e a Jacob Seneor, judio, habitant en la ciudat de Çaragoça, antramos ensemble a cada uno dellos por si, a los quales do e atribuesco pleno poder de inventariar, partir, dividir e diffinir et de si todo aquel poder que a tutores e curadores testamentarios se puede dar e atribuir, segunt fuero, uso e costumbre de Aragon et segunt ley e ritu de judios.

Item lexo exsecutores e spondaleros a ellos mesmo.

Testes: don Pascual Onzina civis, maestre Sento Cavatierra, metge, e Mose Xuen, sastre, judios habitantes Osce. 
$3 b i s$

1445, abril 12, Huesca

Renuncia de Martín Pastor, hermano del finado, renuncia en sus sobrinos, los hijos de Çazon Mazoch, sus derechos como heredero de este. En caso de fallecimiento de uno de ellos, dichos bienes revertirían en favor de su tío Martín Pastor o de alguno de sus descendientes.

AHPH, prot. 84 (notario Juan de Ara), fols. 100v-101r

${ }_{111}$ Renunciacion de los fillyos de Çazon Mazoch.

Eadem die Osce, que yo Martin Pastor, mayor de dias, mercadero, vecino de la ciudat de Huesca, asi como heredero universal qui so de todos los bienes mobles e sedientes, etc., que fueron de Çazon Mazoch, alias Pastor, judio, ermano mio, habitant quondam en la dita ciudat, segunt consta por carta publica de testament, feyto en la ciudat de Huesca a cinquo dias del mes present de abril del anyo present e infrascripto, recebida e testeficada por el notario infrascripto, con voluntat de Aldonca de Ruesta, muller mia, paresco de mi cierta sciencia e agradable voluntat, por algunas cosas justas, mi animo induzientes, renuncio e transpuerto en vos, Reyna e Abraymico Mazoch, nietos mios e fillyos del dito Çazon, todo e qualquiere part e dreyto a mi pertenescient como heredero sobredito en los bienes sitios que fueron del dito Çazon, quondam, ermano mio. Et enpero en tal condicion que si esdevenia de morir alguno de los sobreditos Reyna o Abraymico, que los bienes viengan al sobrebivient, et si contecia morir entramos ante de matrimonio, que los ditos ${ }_{111 v}$ bienes tornen a mi dito Martin Pastor o a mis herederos e succesores en mis bienes. Et yo dita Aldonça de Ruesta, muller del dito Martin, loho, aprovo, etc.

Testes: Johan de Monsserrat e Martin Lorenz, texidor e Salamon Anpinaz, judio, habitantes Osce.

1445, enero 31, Huesca

Testamento de Ezter de Monçón, viuda de Lopu Alffrangí. Deja como heredero universal a su sobrino Jentó Alfrangí.

AHPH, prot. 84 (notario Juan de Ara), fols. 36r-v

${ }_{36 r}$ Testament de Ezter de Monçon.

SEFARAD, vol. 71:2, julio-diciembre 2011, págs. 435-469. ISSN: 00037-0894. doi: 10.3989/sefarad.011.014 
In Dei nomine amen. Eodem die Osce.

Que yo, Ezter de Monçon, muller de Lopu Alffrangi, quondam, judio de la ciudat de Huesca, estando enferma de mi persona e casando e anulando, etc., ordeno el present mi ultimo testament, etc., et si vale por via de testament, sino valga por via de codicillo, en el qual ordeno e departo en la forma e manera siguient:

Et primerament, eslio mi sepultura en aquel fosal en do se costumbran enterrar los otros judios de la dita ciudat, en do jazen mis parientes.

Item quiero, mando e ordeno que mi defunsion me sia feyta segunt costumbran fazer en la dita ciudat.

Item quiero que sian pagados todos mis deudos e injurias, todos aquellos que por verdat seran trobados.

Item lexo a los fillos e fillyas de Bernart de Monçon, quondam, ermano mio, diez sueldos dineros jacceses.

Item mas lexo a Gabriel Monçon, ermano mio, vezino de Montalvan, otros diez sueldos dineros jacceses. Et quiero que con aquesto se tiengan por contentos e pagados de toda e qualquiere part e dreyto que ellos e qualquiere delos podiesen haver o alcançar en mis bienes asi mobles como sedientes.

Item quiero ${ }_{36 v}$ mando e ordeno que sia feyta huna tomba pora la fuesa de don Jacob Baço e otra pora la fuesa de don Haym Alcocombriel, las quales costen cada una cada tres florines.

Item quiero e ordeno que sobre mi fuesa sia posada una lieua.

Item lexo a la misnera $[\mathrm{sic}]$ do cayere tres sueldos.

Item mas lexo a la confraria que lievan los muertos otros tres sueldos.

Item complidas todas e cada hunas cosas sobreditas de parte e de suso nombradas e specifficadas e por mi mandas [sic] fazer todos e qualesquiere otros bienes mios assi mobles como sedientes, dreytos, nombres e acciones a mi pertenescientes dentro en el regno de Aragon, etc., lexolos todos a Jento Alfrangi, nieto mio e fillyo del sobredito Lopu, marido mio, /e de Oro Monçon, ermana $\mathrm{mia} /$, al qual instituesco heredero mio universal.

Item lexo spondalero mio a Symuel Yrica, judio Osce.

Testes: Domingo Mallen, texidor, Abrayme Alfaguel e Azarhea Aldich, judios Osce.

1446, abril 14, Huesca

Testamento de Simuel Havingastón, judio de Huesca, dejando como heredero universal a su hijo Haym Avingastón. 
AHPH, prot. 189 (notario Juan Ascaso), fols. 62r-63v

${ }_{62 r}$ Testament.

En el nombre de nuestro Senyor Dios e de la su gracia amen. Como toda persona en carne puesta a la muert corporal sia subjugada por el peccado que el primer hombre, stando em parayso terrenal perpetro en traspassar el mandamiento de su Creador, e por seguient en la creatura no sia cosa mas cierta que la muert e menos cierta que la hora de aquella, por tanto yo, Simuel Havingaston, judio habitant en la ciudat de Huesca, seyendo apasionado algun tanto de mi persona, empero seyendo, lohado el Senyor Dios, en mi buen seso, firme memoria, sano entendimiento e lo que la maniffiesta, temiendo morir e queriendo evitar las penas inffernales e copdiçiando hir a su santa gloria, e por tal que questiones ni debates no puedan seyer movidos entre mis cercanos parientes en e sobre mis bienes. Por ${ }_{62 v}$ tanto, revocando todos e qualesquiere otros testamentos, etc., ordeno aquest mi ultimo testament dius la forma seguien:

Et primerament quiero, mando, e ordeno que cada e quando mi anima sera passada deste mundo al otro, que mi cuerpo sia enterrado en el cimenterio, siquiere fossar de los judios de la ciudat sobredita, sito en Sant Jorge, en aquell lugar do a los spondaleros mios diuso scriptos sera visto con aquella solempnidat e cerimonia, segunt costumbre judaica que a los ditos spondaleros mios sera visto.

Item mas quiero, mando et ordeno que de mis bienes sian sateffeytos e pagados por los spondaleros inffra scriptos todos mis deudos, injurias e tuertos que por verdat seran trobados yo sere tenido.

Item mas quiero, mando et ordeno que Bonaffillya, muller mia durant tiempo de su vida, finque e sia senyora e mayora de todos mis bienes, assi mobles como sedientes, sienes de alguna contradicion de mi heredero diuso scripto e de qualquiere otra persona, empero que ella no pueda ordenar ni disponer de aquellos apres ${ }_{63 r}$ sus dias en persona alguna, exceptado que si durant vida suya por sustentacion de su persona haura meester a socorrerse de los ditos bienes, que ella pueda prehender aquellyo que sera conocido por los dayanes que de present son o por tiempo seran de la juderia de la ciudat sobredita, et por tal que los bienes sian conservados, quiero que durant vida de la dita Bonaffillya el heredero mio dius scripto no pueda vender, transportar ni alienar ni en si prehender en todo ni en part de los ditos bienes, assi mobles como sedientes si no yes con voluntat e expresso consentimiento de la dita Bonaffilla, muller mia.

Item mas quiero, mando e ordeno que sobre las sepulturas de mi muller Bonafilla e mia que nos sian feytas sendas tombas por mi heredero dius scripto, cada e quando pora e a el visto sera. 
Item sateffeytas todas e cada una cosas sobreditas, apres dias de la dita Bonaffilla, muller mia, lexo heredero universal mio a Haym Havingaston, judio fillyo mio, al qual instituesco heredero mio universal de todos mis bienes, assi mobles ${ }_{63 v}$ e sedientes, dreytos, nombres e acciones mias.

Item lexo spondaleros e complidores del present mi testament e cosas en el contenidas a los sobreditos Bonaffilla, muller mia, y Haym Havingaston /fillyo mio/ judios; dandoles todo aquell poder por acomplir e exseguir el dito testament e cosas en aquell contenidas qui a spondaleros, segunt dreyto e ritu de judios yes dado e atribuido a spondaleros testamentarios a Dios nuestro Senyor e a los quales carament comando mi anima, rogandoles que les [ileg.] de mi anima, en tal manera que de Dios nuestro senyor en este mundo ende hayan buen gualardon e en el otro vida perdurable amen. Feyto fue aquesto en la ciudat de Huesca a XIIII del mes de abrill, anno a nativitate Domini millessimo CCCC XXXX sexto, dia sobredito. La dita Bonaffilla loha e aprova el sobredito testament.

אני שמוץ גשתון לואה אי איפאה אל כתיב לעיל. קתבתי מידי.

[Yo, Šemuel Gastón, loa e epa [sic, por aproba] el escrito previo. Lo escribí de mi mano $]^{22}$.

Testimonios fueron desto don Pero d'Aspa ciudadano et Acach Biuag, judio, habitantes en Huesca.

1451, enero 30, Huesca

Testamento de Rina de Alcocombriel, viuda de R. Salamón Leví.

AHPH, prot. 89 (not. Juan de Ara), fol. 35r-v

${ }_{35 r}$ Testament de Rina de Alcocombriel.

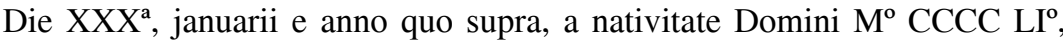
Osce.

Que yo, Rina d'Alcocombriel, vidua, muller qui fue de Rabi Salamon, judio quondam habitant en la ciudat de Huesca, estando enferma de mi persona e loado el nombre de nuestro senyor Dios, seyendo en mi buen seso, etc., casando e anullando, etc., ordeno el present mi ultimo testament.

${ }^{22}$ Agradezco al Sr. Jaume Riera su asistencia en la comprensión de la suscripción hebraica. 
Et primerament eslio mi sepultura en aquel fosar en do se costumbran enterrar los otros judios de la dita ciudat.

Item quiero mando e ordeno que mis defunsion, novena e d'anyo me sian feytos a ordinacion de mis spondaleros, etc.

Item quiero mando, etc., que todos deudos e injurias sian satisfeytos e pagados todos aquellos que por verdat sian trobados, etc.

Item lexo lexo [sic] ad Astruga Leui, fillya de Rabi Salamon, quondam, muller de David de las Yfantas /por el seruicio que me ha feyto/ cinquo florins de oro. Item mas vna gonellya de las mias, la millor.

Item lexo a la muller de Astruch Cogombriel, clamada Astruga Hauin, por el seruicio que me an feyto dos florins.

Item quiero, mando e ordeno que sian feytas dos tombas sobre las fuesas de dos fillyos mios clamados Jucefi Almarran e Astruch Levi, /e otra para mi, dita Rina/.

Item lexo a la mismart [isic?] que faran mi fuesa $\mathrm{X}$ sueldos et que sian tenidos fazer la fuesa cerca la del dito rabi Salamon marido mio.

${ }_{35 v}$ Item conplidas todas e cada unas cosas sobre ditas e por mi mandadas fazer e todos e qualesquiere otros bienes mios, assi mobles como sedientes et dentro en el regno de Aragon e fuera de aquel en qualsquier ciudades, villyas, etc., lexolos todos a Mose Almarran, fillyo mio e de Mose Almarran, marido mio primero, quondam, al qual instituesco heredero mio universal. Et si contecera morir el dito Mose, fillyo mio, menor de edat o intestado, que en los ditos casos e qualquiere dellos los ditos bienes sian distribuydos e partidos en la forma siguient: es quende sian dados a la dita Astruga Leui, muller del dito David de las Ynfantas, trenta florins e cinquo florins al dito Astruch Cogombriel, et del residuo que sia todo distribuydo por mi anima a ordinacion de mis spondaleros infrascriptos.

Item lexo tutor e curador de la persona e bienes del dito Mose Almarran, fillyo mio, a don Simuel Usiello, judio habitant en la dita ciudat, etc.

Item lexo spondaleros e complidores del present mi ultimo testament al dito don Symuel Usiellyo e a Mose Ardit, judio de la dita ciudat, etc., antramos ensemble e cada uno dellos por si, dandoles todo aquel poder, etc. Fiat large.

Testes: Symon d'Arguis ciuis, rabi Jucen Albachli e Abrayme Altissiffi, alias del Bayo, judios Osce. 
1456, abril 18, Huesca

Últimas voluntades de Soli Cohen, viuda de Acach Leví. Le precede una Difinicion ['absolución'] suya justificando a su hijo, Abrayme Leví (al que deja de «spondalero»), en la ayuda que le presta. Sigue el texto de su testamento.

AHPH, prot. 195 (notario Juan Ascaso), fols. 67v-69v

${ }_{67 v}$ Diffinicion.

Die predicta. Que yo Soli Cohen, filla de Juce Cohen /judia/, muller que fue de Acach Leui, judio quondam habitant en la ciudat de Huesca, de mi cierta sciencia atorgo haver havido e en poder mio recebido de vos Abrayme Leui judio, fillo mio, todos e qualesquiere bienes e dineros que vos me fuesedes tenido dar e restituir, etc. ${ }_{68 r}$ los quales bienes yo dita Soli he cobrado et preso de vos dito Abrayme por a governamiento e sustentacion mia e otras necessidades mias. Et con aquesto vos absuelvo, quito, relaxo e diffinesco a vos e a vuestros bienes de qualquier peticion, etc., dius obligacion de todos mis bienes mobles e sedientes, havidos e por haver, etc., e no res menos presto quinyan complido en poder de los testes judios, dius scriptos de tener lo sobredito, etc.

Testes: Garcia Cariella et Acach Abbadias e Abrayme Xuen, texidor judio Osce.

\section{${ }_{68 r}$ Testament}

Die predicto.

En el nombre de Dios e de la su gracia, amen. Como toda persona en carne puesta a la muerte corporal scapar no pueda e no sia cosa mas cierta que la muert e menos cierta que la hora de aquella, por esto sia maniffiesto a todos que yo, Soli Cohen, judia, filla de Juce Cohen e muller de Acach Leui, judio, quondam habitando en la ciudat de Huesca, seyendo enfferma de mi persona en pero en mi buen seso, entendimiento, etc. ${ }_{68 v}$ e temiendo morir, etc., e revocando ex causa todos e qualesquiere testamentos, etc., fago e ordeno aquest mi ultimo testament, etc., dius la forma seguient:

Et primerament attendido que yo no tiengo ni possido sino muy pocos bienes que son en valua si quiere extima de qualesquier cient cinquanta sueldos, poco mas o menos, los quales bienes me finquoron del dito Acach Leui, marido mio, abatidas las expenssas de su enterritorio e sateffeytas sus injurias, que el dito Acach era tenido satiffer, e visto assi mesmo que yo haure de meter para mi interritorio cada 
e quando al senyor Dios sera plazient que yo sere passada deste mundo al otro, por tanto quiero disponer e ordenar de aquellos dius la forma seguient:

Et primerament quiero, mando e ordeno que cada e quando a Dios sera plazient que yo sere finada, que mi cuerpo sia enterrado en el cimenterio de los judios de la dita ciudat, cerca el dito Acac Leui marido mío, el qual enterritorio sia feyto de los ditos ${ }_{69 r}$ mis bienes, segunt que ad Abrayme Leui, fillo mio, espondalero mio, sera bien visto a su voluntat.

Item quiero que de mis bienes sian pagados e sateffeytas todas mis injurias, que yo sere tenida verdaderament.

Item lexo a Johan de Viturian, cristiano, fillo mio, e al dito Abrayme Leui, fillo mio, assi mesmo, cada diez sueldos dineros jacceses de legitima, assaber cada cinquo sueldos por bienes mobles e otros cada cinquo sueldos de bienes sedientes. Et con aquesto quiero que cada uno dellos se tienga por pagado e contento de qualquiere part de legitima, que cada uno dellos podies haver en mis bienes mobles e sedientes.

Item lexo a mi Jamila Leui, filla mia, muller de Acac Alguer, mi manto de bruneta.

Item lexo a la muller del dito Johan de Viturian mi grimen negro, forrado de penya blanca.

Item lexo a la muller del dito Abrayme una saya mia jusana de bruneta.

Item sateffeitas e complidas todas e cada ${ }_{69_{v}}$ unas sobreditas de todos los otros mis bienes que sobraran, lexolos por mi anima, los quales sian distribuydos por el dito Abrayme Leui, fillo e espondalero mio infrascripto, segunt que a el plazera e a todas sus voluntades, a la qual voluntat quiero que ninguno no le pueda contradir ni contrastar.

Item por acomplir e seguir el present mi ultimo testament, lexo spondalero mio al dito Abrayme, etc.

Testes los sobreditos.

8

1462, febrero 6, Huesca

Testamento de Jucé Luytanes, marido de Ester Parello, a la que deja como heredera universal.

AHPH, prot. 198 (notario Juan Ascaso), fols. 17v19r 


\section{${ }_{17 v}$ Testament}

Die sexta, menssis febroarii.

En el nombre Dios todopoderoso e de la gracia /trayo in forma/ e misericordia suya amen. Como toda persona en carne puesta a la muert corporal scapar non pueda, e no sia cosa mas cierta que la muert e menos cierta que la hora de aquella, por tanto sia maniffiesto a todos que yo, Juce Luytanes, judio habitant en la ciudat de Huesca, seyendo enffermo de mi persona, enpero lohado nuestro senyor Dio, stando en mi buen seso, firme memoria e entendimiento e lo que la manifiesta temiendo morir, queriendo evitar las penas inffernales e copdiciando de hir a la santa gloria de paradisso et por tal que pleyto, question e debites entre mis cercanos parientes non puedan seyer insurgidos revocando todos e qualesquiere testament o testamentos, codicillo o codicillos por mi antes de agora feytos, fago e ordeno aquest mi ultimo testament, mi ultima voluntat e postrema ordinacion de mi e de todos mis bienes mobles e sedientes, etc., el qual quiero que valga, etc.:

${ }_{18 r}$ Primerament quiero, mando e ordeno que cada e quando a Dios mi senyor Dios plazera que al senyor Dios plazera [sic], que mi anima sera passada deste mundo al otro, que mi cuerpo sia enterrado en el ciminterio de los judios de la dita ciudat, cerca do jacçe Alazar Luytanes, hermano mio, en do me sian feyta toda mi funeralia de mi deffunsion, novena e cabo d'anyo segunt costumbre e uso de judios.

Item mas, que mando, quiero e ordeno que de mis bienes sian pagados e sateffeitas todas mis injurias, devidas e tuertos que por verdat seran trobadas yo seyer tenidos.

Item mas, de todos los otros mis bienes mobles e sedientes, dreytos, nombres, vozes e acciones mias e a mi pertenescientes e acatantes pertenecer e acatar podientes e devientes con cartas e sines de cartas por qualquiere otro dreyto, titol, caso, manera o razon de panes, vinyas, dineros e deudos a mi devidos, lexolos a Ester Parello, muller mia a la qual lexo heredera mia universal e senyora mayora, de los quales pueda disponer e ordenar a todas sus propias voluntades.

Item mas, lexo spondaleros mios e complidores del present ultimo testament a don maestre- ${ }_{18 v}$ Astrueh Hatrinardut, fisigo, Aeae Parexoe Aeae de Pina.

Item mas, quiero que del huerto que yes contiguo a las casas de mi habitacion sito en la dita juderia a la carrera de las Fuentes, confronta el dito huerto con parral de micer Johan de Gurrea de dos partes, con huerto de Mosse Cohen, con huerto de Jento Alfrangi, que ende sia dado el dito huerto a Horo Luytanes, filla mia e muller de Acac de Pina, hueyto coudos d'amplo, al qual de gracia special lexo aquellos hueyto coudos del dito huerto, encargo a la dita Ester Parello, 
muller e heredera mia, que le de francament e libera por bien de part e buena concordia de todos.

Item mas, lexo a Johan d'Ara, neofito, hermano, de mis bienes XV sueldos dineros jaqueses, con los quales quiero que se tenga por contento de qualquiere dreyto quel podade haver de mis bienes, assi mobles como sedientes.

Item mas, lexo spondaleros e exsecutores del present mi ultimo testament a los honorables e caros amigos mios don maestre Astruc Hauinardut, fisigo, Acac Parexo, e Acac de Pina, judios habitantes en la ciudat de Huesca, a los quales do pleno et bastant poder por acomplir e en todo aquell poder que a spondaleros testamentarios, segunt dreyto, uso, ritu e ordinacion de judios e de fuero yes dado. E a Dios e a los quales carament comando mi anima, etc.

Presentes testimonios fueron d'esto: don Pedro d'Agon clerigo benefficiado en la Seu de Huesca e Salamon Adder, judio habitant en Huesca.

\section{${ }_{19 r}$ Codicillo}

Die predicta. Como licita cosa sia a qualquiere persona por codillo, etc., de sacar e ahanyadir de su vltimo testament, etc., por tanto yo, Juce Luytanes, anyade e do a su ultimo testament et lexa a Johan d'Ara, hermano suyo habitant:

Diez sueldos dineros jacceses de part de legitima e de qualquier dreyto qui el podiesse haver ni alcançar en mis bienes, assaber es cinquo sueldos por bienes mobles e cinquo sueldos por bienes sedientes, con los quales diez sueldos quiero que se tienga por pagado e contento de qualquiere part e dreyto qui el por legitima e pertenesce en mis bienes podiese haver ni alcançar, ratifficando e corroborando el dito mi último testament que en todo e por todo que finque e romanga en su firmeza e valor, etc.

Presentes testes fueron desto maestre Garcia de Heredia e Salamon Hanoca, fillo de Mosse Hanoca, alias de las Infantas, judio, habitantes en Huesca.

9

1466, octubre 18, Huesca

La aljama nombra procuradores para que puedan gestionar la herencia que en sus últimas voluntades y a favor de dicha aljama había dejado el fallecido Salamón Cazez, habitante en el reino de Sicilia.

AHPH, prot. 74 (notario Antón Bardaxí), fols. 37r-v 
${ }_{37 r}$ XVIII octubris. Procura. Sia manifiesto a todos que clamada, cridada e ajustada publicament la aljama de los jodios de la ciudat de Huesca por voz de Açach Orella, nuncio publico de la aljama e por mandamiento de los adelantados de aquella segunt quel dito Acach Orella, nuncio sobredito, tal fe e relacion fizo a mi, notario, inffrascriptos presentes los testimonios inffrascriptos e plegada la dita aljama dentro del patio de la sinoga mayor de la dita aljama por mandamiento de los ditos adelantados, do e segunt que otras vegadas es acostumbrada plegar e clamar e ajustarse la dita aljama, presentes e intervinientes:

don Acach el Nieto,

don Jehuda Cavatierra, adelantado,

don Acah Argilet, dayan,

maestre Astruch Cohen,

maestre Mosse Rondi,

Abrayme Alentienz,

Elezar Adder,

Azarian Xuen,
Acach Cocumbriel,

Ahim Figell,

Aym Turtuzo [¿sic, por Tortoxí?],

Inssua Eriza,

Mosse Cocumbriel,

Juce Natan,

Simuel Xuen,

Juce Albachli,

procuradores, siquiere regidores qui se dicen seyer e la dita aljama.

Samuel Levi,

Salamon Azunana,

Acach Viuago,

Juce Xuen,

Juce Allaquen,

Jacob Zuri,
Astruch Muçanuno,

Simuel Aym,

Mosse Natan,

Simuel Xuen, menor,

Junez Açaz,

Inssua Abadias,

Acach Qualit,

Bonafos Parecho,

jodios de la dita aljama de la sobredita ciudat, et de si toda la aljama de los jodios de la dita ciudat stantes, plegados, aljamantes e aljama fazientes por nos e por los nuestros presentes e por los absentes e aduenideros, nos, toda la aljama e los singulares de aquella, todos ensemble e cada uno de nos por si e por ell todo, universalment non revocando los otros procuradores por nos e la dita aljama ante de 
agora feytos, constituydos, creados e ordenados de nuestras sciertas sciencias e de cada uno de nos e de la dita aljama, fazemos, constituimos, creamos e ordenamos sciertos speciales e generales procuradores nuestros e de la dita aljama, son a saber a los honorables don Mose Catorze e a Mosse Passagon, jodios de la aljama de la ciudat de Calatayut, absentes, bien como si fuessen presentes a entramos ensemble e cada uno dellos. Specialment e expressament a demandar por si, ansi que no sia mylor [sic] la condicion del present que del absent ante que quiere que por el vno dellos ser fecho por el otro pueda seyer continuado mediado finido e determinado ${ }_{37 v}$ hauer, recebir e cobrar por nos e por la aljama, todas e qualesquiere cuantias de dineros e florines e otros cualsequiere bienes de qualesquiere natura, specie sean lexados en el ultimo testament de Salamon Cazez, jodio, quondam, habitant en los regnos de Sicilia o en qualquiere otra manera lexados a la dita aljama sian si a la sinoga mayor de aquella como a las otras sinogas e spitals de la dita aljama, e de lo que recibran por nos e por la dita aljama puedan atorgar albaran o albaranes, apochas, difiniciones tantos quantos seran necessarios a la part o partes de quien sera interes; et no res menos por la dita razon puedan comprometer absolutament qualsequiere pleytos, questiones e debates que de present sean o speran seyer sobre las ditas quantidades e bienes sobreditos, con qualquiere persona de qualquiere ley, stado, grado o condicion, sian en poder de aquella persona o personas e por aquell tiempo o tiempos e jus aquella pena o penas e juramentos e que visto les sera e loar e aprobar qualsequiere sentencia que por la dita razon se dara. Et desia [isic?] pleytos large cum pose, jurando etc., jus obligaciones, etc.

1472, febrero 3, Huesca

Testamento de Astruga Acocumbriel, viuda de Simuel Avín.

AHPH, prot. 66 (notario Juan Beltrán), fols. 35r-v

${ }_{35 r}$ Testament de Astruga Avin.

[ad marginem: forma] Die predicto. Que yo Astruga Avin, muller de Simuel Avin, judia, viuda, Osce, stando enfferma, etc., et seyendo en mi buen seso, etc., fago el present mi testament, revocando, etc., e dius la forma siguient:

Et primerament toda ora cada e quando yo finara mi cuerpo sea sepellido en el fosar de los judíos Osce.

Item quiero que todos mis deudos sean satiffeytos, etc. 
${ }_{35}$ Item quiero que sean dados a don Martin de Risco, clerigo Osce, vint sueldos que por deudo de parentesco, con los quales se tenga contento, etc.

Item quiero que sean dados [a] Pedro [en blanco] nieto mio, por deudo de parentesco $\mathrm{V}$ sueldos, etc.

Hem lexo a Salamon, Simuel, Juee e Soli, e a su hermano nietos mios e de Astruga Cocumbriel, eada V streldos, con los quales, ete.

Item lexo a Rahel, muller de Haym Alcastiel de Ayerbe, nieta mía, V sueldos con los quales, etc., e huna toca negra escura e huna piel. Item mas, biene a servir ella [¿sic?] donde de mas que yo men descargare [¿sic?].

Item satiffeytas e complidos todas e cada unas cosas sobreditas, etc., todos los otros bienes mios mobles e sedientes, etc., por los servicios feytos e fazederos, etc., dexolos a Salamon e Simuel, Juce e Soli Acocumbriel, hermanos, fillos de Astruch Cocumbriel, por respecto del anima del dito Simuel e mia, a los quales fago herederos, que partan por iguales partes.

Item lexo a Aymano Alterteffi e a Orduenya, filla suya, por deudos de parentesco cada $\mathrm{V}$ sueldos con los quales, etc.

Testes; Lorenz Burro, Alazar Adder e Jacob Rogat, çapatero.

1477, enero 24, Huesca

Los adelantados de la aljama de Huesca requieren al lugarteniente de baile de la ciudad la entrega de los bienes de [los hijos de] Mossé Hadida, el cual había fallecido intestado (y en consecuencia sus bienes habían pasado a ser propiedad del rey). Se incluye acta de la ejecución de unos bienes hallados en casa del finado.

AHPH, prot. 233 (notario Juan de la Fuente), fols. 13v-14r

${ }_{13 v}$ Dicta die Osce, Salamon de las Ynfantas e Acach Biuag, adelantados de los judios Osce e don Gento Argelet, lugartenient por Abrayme Argelet, adelantado Osce, requerieron al dito lugartenient de bayle [ileg.] e tornase a manos suyas los bienes de los fillyos de Mosse Hadida, quondam, e por cumplimiento e por el antedicho.

Testes: Pedro de Urroy e Acach Hayeno, alias Orellya, judio habitante Osce. ${ }_{14 r}$ Exsecucion. 
Dicta die [24 januarii] Osce. Dentro en las casas que fueron del dito Mosse Hadida, sitas en la juderia, en el barrio de Amalbel, que confrontan con casas de Juce Herica e con carrera publica e con callyço que no ha salida, el dito lugartenient de bayle, por vigor de la dita requisicion, fizo abrir con las claves del senyor Rey vn palacio, el qual fue trobado cerrado con clau e asi abierto a complimiento de la dita [ileg.] exsecuto los bienes siguientes en presencia de Geuda Cavatierra:

Item mas vn cofre ferrado con un trauesero delante. Item dos pares de lincuelos d'estopa, dos touallyas, vn touallyon de stopa, vn Genesi en ebrayco, vn liuro de Profecias de Isayas adelant.

Item vn embudo d'arambre.

Item vna ligarca de cartas de comandas, deudos; e otras que son XXXXI carta, vn fogaril, vn caxon de fusta, vn fogaril de fierro, vna gradola remalega, vna tabla de comer con sus piedes e con vn bancal encima armas nobles, dos tirantes con dos bagas, vn bolson de lienzo negro pintado, vn liuro de deudas scripto en judayco.

Item una caxeta con XXXI carta de comandas e otras, otro libro de deudas, dos castanyas de vidre, vna perfila [ileg.], $\mathrm{X}$ trocos de [ileg.] e diversos e otras cartas fueron [ileg.]; vna carta de un lugar de la sinoga de Sant Cebrian [sic], otro fogaril grant.

Testes qui supra.

1478, julio 7, Huesca

Testamento de doña Bienvenida Almagén, viuda de Acaz Gualit, pellicero de Huesca. Sigue un inventario de sus bienes.

AHPH, prot. 315 (notario Blas Colduras), fols.134r-v

${ }_{134 r}$ Testament dona Bienvenida, uidua, mullyer que fue de don Acaz Gualyt, judío, pelycero, Osce.

En el nombre de Dios. Dona Bienvenida, uidua, mullyer que fue de don Acach Guallyt, fillya de don Mosse Almagen, quondam, fago el present mi testament, que sigue:

Primero lexa en los mellyores bienes mobles suyos que de aquellyos sia feyto su mortario e su atahut. Et prima [sic] toma e pagades los rabis por su anima. 
Item lixo a don Martin de Florenza, capellyan, habitant en la villya de Pertusa, diez sueldos, e a las hermanas del dito Martin de Florenza o otros ermanos e qualquiere otro cossino o cosino que se provara seyer, lexo cada cinquo sueldos a cada huno por part de bienes paternales e maternales.

Item lexo a Jamyla, mullyer de Abrayme Alcastiel, mayor de dias, por los treballyos que a avido en servirme, trenta sueldos del mellyor que sy trobara.

Item lexo carga del mi mortorio e de mi tom[b]a, que sia feyta dentro l'anyo que sia morta a Jacob Ardit e ha Abram Alcastiel e a May[r] Natan.

Item lexo a Hezmel Gualit, fillyo de Jacob Gualit, vint sueldos para huna dogra [isic?] por [aquí termina la frase].

Item a Jamilica, fillya del dito Jacob, lexo cinquo sueldos con los quales le compren huna saya.

Item lexo a Juce Natan, menor, diez sueldos.

Item lexo a Jacob Ardit, fillyo de Abrayme Ardit, trenta sueldos.

Item lexo a Salamon Atan, diez sueldos si seran.

Item lexo a Mosse Nata[n], quinze sueldos.

Todo lo restant lexo a Gento Natan e a Maye [sic] Nata[n] yguales partes.

Actum Osce, dia martes a siet de julyo, anyo setanta e güeyto.

Testes: Ananya Rogat e Junez Acaz e Loys de Medina.

Yo dita Bienvenida quiero e mando que aquellyas enbaxas las quales sin companiadas [isic?] segunt paresce pora Albagli Natan et testimonio Gento Abadias, quedando la cantidat, ran [sic] lineadas a las partes. quondam.

${ }_{134 v}$ Inventario de los bienes de Bienvenida, vidua, mullyer de Acach Guallit,

Primo en el palacio hun almario que en el qual fue trobado carado.

Item en los tres almarios del palacio baxo fue trobado: en el mas alto huna calderica de arambre con dos ansas, todo arambre.

Item fue trobado en el almario vaxo hun porcadero [o porgadero] de arambre.

En la caxa era cerrada con clau, fue huna ropa negra forada de cardeno, otra ropa negra forrada de tela negra.

Item lincelo de stopa, hunas tovallyonas con listas cardenas .

Item huna calderuela toda de arambre.

Fue trobado en pecunia, reales, carlynes e monedas, todo cient e quarta ocho sueldos e diez dineros, mas prenden xixanta pora su mortallya. 
Tres florins e medio de oro en oro e tres cullyaretes e mas quatro en hun stug e tres reales en l'estug, setze mas.

Item hun bancal viexo.

Item hun calderuelo crebado.

Item hun mortero de carne chyquo con su mano.

Item hun rellyo de canyamo, mas dos dotzenas e media de canyamo e medio tadua [isic?] engarado.

Huna mantequera viellya negra.

Hun manto negro; una cubierta.

Item la caxa do stavan los ditos bienes.

Item hun leyto de fusta; huna linteruela.

Item hun travessero.

Actum Osce, a nou dias de julyo, anno M CCCC setanta e gueyto.

Testes: Nahamen Zuri, pellycero et Francisquo de Palencia, cilurgiano.

Recibido: 07/01/2011

Aceptado: 30/11/2011 